\title{
An Electrophysiological Probe of Incidental Semantic Association
}

\author{
Marta Kutas and Steven A. Hillyard \\ Department of Neurosciences \\ University of California, San Diego
}

\begin{abstract}
Long-latency components of event-related brain potentials (ERPs) recorded from subjects reading meaningful text are sensitive to semantic relationships among the major lexical items of sentences. In particular, the N400 components are enlarged to words that are semantically unrelated to or incongruous with the context provided by preceding items in a sentence. The present experiment was aimed at finding out whether this inverse relationship between N400 amplitude and semantic association would extend to situations where words were presented in isolated pairs, using a design that dissociated changes in $\mathrm{N} 400$ from confounding ERP waves elicited by active decision making. ERPs were recorded to 320 word pairs presented to eleven subjects. Each pair of words was followed by a letter, and subjects made a differential response according to whether or not the letter had been present in either of the words. After the ERP recording session, subjects rated the degree of semantic association between the words in each pair. ERP averages were formed on the basis of the subjects' ratings and on the basis of normative, a priori categories. For both types of averages the N400 amplitude was found to be a sensitive index of semantic association, even though the association was incidental to the subject's assigned task. These findings suggest the utility of the $\mathrm{N} 400$ measure in studies of semantic priming and as a probe of the automaticity of contextual influences in language processing.
\end{abstract}

\section{Introduction}

Laboratory observations have tended to confirm our everyday experience that words are not always as easily understood in isolation as in the company of other words. For example, we can usually decipher a word through static in a phone line or through smudges on a billboard more readily if there are other words close by that define a context in which this "degraded" material is to be understood (e.g., Becker \& Killion 1977; Grosjean 1980; Miller, Heise \& Lichten 1951; Norris 1984; Tulving \& Gold 1963). Similarly, we are able to use the meaning of a word we know to help reveal the meaning of another we do not know. However, it is much less obvious how or ,according to some theorists even whether, we use contextual information in the recognition of familiar words during our everyday readings and conversations (Forster 1981; Henderson 1982; Mitchell \& Green 1978).

Psycholinguistic investigations over the years have demonstrated that it takes less time to decide that a string of letters is a word (i.e., lexical decision) if it is immediately preceded by a related word than if the preceding word is unrelated (e.g., Meyer, Schvaneveldt \& Ruddy 1974). The time taken to say a word aloud (i.e., pronunciation or naming latency task) is similarly speeded up by a preceding associate (e.g., Meyer, Schvaneveldt \& Ruddy 1975). A number of relations between words including identity, similar appearance, similar sound, having a similar root, or associations based on syntactic and semantic usage have been shown to facilitate lexical decision and pronunciation latencies. Of major interest for present purposes are the findings that point to the importance of semantic associations between words in facilitating responses (i.e., semantic priming). In most situations the presence of semantic association between two words is beneficial to task performance (e.g., Meyer et al. 1975; Neely 1977), although in some cases the reverse occurs (e.g., Brown 1981; Blaxton \& Neely 1983). 
While specific details of the proposed mechanisms underlying semantic priming effects vary, it is widely held that such effects reflect the functional organization of semantic memory. In this view, one consequence of having "accessed" a given lexical entry is an automatic spread of activation to highly associated entries in the mental lexicon (c.f., Collins \& Loftus 1975). Evidence for the relative contributions of automatic and attentional processes to semantic priming effects is mixed (e.g., Antos 1979; de Groot 1984; Neely 1977; Seidenberg, Waters, Sanders \& Langer 1984). This inconsistency of findings stems, in part, from the fact that the experimental effects used to support particular hypotheses about lexical access are not independent of the task manipulations. For example, under similar conditions, larger priming (facilitatory and inhibitory) effects are found during lexical decision than naming tasks, although only naming tasks show mediated priming ${ }^{1}$ (e.g., Balota \& Lorch 1986; Lorch, Balota \& Stamm 1986; West \& Stanovich 1982). For some researchers, this result has led to continued re-evaluation of procedures for inferring lexical access or activation and inhibition (e.g. Lorch et al. 1986), whereas for others it has formed the basis for the argument that only naming tasks can provide a "pure" estimate of access (Balota \& Chumbley 1984; Seidenberg et al. 1984). There are still others for whom such discrepancies call for other approaches to the issue (e.g. Swinney 1981; Schustack, Ehrlich \& Rayner 1987; Kutas \& Van Petten, in press).

Psychophysiological methods have recently been applied to the analysis of language mechanisms, in particular the measurement of brain electrical activity that is time-locked to the underlying processing events of interest. Specific patterns of brain wave activity have been identified in the scalp-recorded electroencephalogram that are reliable indices of perceptual, cognitive, and linguistic events (for reviews see Donchin et al. 1986; Hillyard and Picton 1987). These "event-related potentials" (ERPs) consist of a series of positive and negative voltage deflections (components) that represent the synchronous activities of neuronal populations engaged in information processing. Under appropriate experimental conditions, ERP data can be useful for demarcating the timing and order of hypothesized processing operations and for distinguishing among serial, parallel and hierarchical forms of analysis (Coles et al. 1985; Hillyard and Hansen 1986; Harter and Aine 1984). Moreover, ERP recordings can yield a record of covert aspects of cognitive and linguistic processing that may or may not lead to overt behavioral responses and may not even reach the level of conscious awareness. Of course, before using an ERP measure (or other physiological index) to test among alternative explanations of a phenomenon such as semantic priming, it is necessary to demonstrate that the ERP in question is reliably influenced by at least some of the factors previously shown to be effective in manipulating the cognitive process under study.

ERP studies of sentence and word processing over the past ten years have demonstrated that a negative component (N400) appearing between 250 and $600 \mathrm{msec}$ following stimulus onset (typically peaking between 350 and 450 $\mathrm{msec}$ ) is sensitive to many of the same experimental manipulations that affect the speed of lexical access (for reviews see Picton \& Stuss 1984; Rugg, Kok, Barrett \& Fischler 1986; Kutas \& Van Petten, in press). All other things being constant, the amplitude of the $\mathrm{N} 400$ wave reflects the degree of semantic association between content or open-class words in sentences (e.g., Fischler, Bloom, Childers, Roucos \& Perry 1983; Fischler, Childers, Achariyapaopan \& Perry 1985; Kutas \& Hillyard 1984; Kutas, Lindamood \& Hillyard 1984). In particular, the N400 component is reduced to the extent that the eliciting word is semantically related to the context provided by the preceding items in the sentence.

The majority of studies with the $\mathrm{N} 400$ have focussed on words presented in sentence contexts (e.g., Kutas, Van Petten \& Besson 1988). However, insofar as ERPs have been recorded during some of the more common behavioral single word or word pair priming paradigms such as lexical decision (Bentin, McCarthy \& Wood, 1985; Holcomb 1986, in press) and category membership judgement tasks (Boddy 1981; Boddy \& Weinberg, 1981; Polich, Vanasse \& Donchin 1981; Harbin, Marsh \& Harvey 1984; Boddy 1986; Neville, Kutas, Chesney \& Schmidt 1986), late negativities similar to sentential N400s have been observed. Under such circumstances, the largest N400s have been seen following unprimed or out-of-category words and "pseudowords" (that is, orthographically legal, pronounceable nonwords). The same words that would be associated with reduced reaction times in a lexical decision task are the ones that are associated with the smallest $\mathrm{N} 400$ components.

In previous studies, these non-sentential N400s were elicited together with an overlapping late positive (P300) component, since the tasks in which they were recorded required a binary decision concerning the lexical status or semantic content of the word. This type of experimental design leads to a basic confound in interpreting the ERP differences between semantically primed and unprimed words; it is not clear to what extent such waveform differences are actually due to variations in N400 amplitude as opposed to shifts in latency of the P300 component associated with decision speed (e.g., Bentin et al. 1985).Moreover, the presence of an overlapping P300 wave has made it difficult to determine the scalp distribution of the $\mathrm{N} 400$ component, which has generally been reported to be more frontal in these word pair paradigms than in sentence situations (e.g., Boddy 1986).

In the present experiment, we utilized a word pair task in which the required decision was delayed well beyond the second word of a pair in order to avoid any overlap between ERP indices of semantic association and the more general decision-related responses such as the P300. Subjects were presented with pairs of words and instructed to read them so that they could decide whether 
a probe letter presented subsequent to each pair had been in either or both of the preceding words. The degree of semantic relationship between the words in a pair was varied systematically; however, subjects were not informed of this variation because it was extraneous to their task. Thus, the main goals of this experiment were to determine: (1) whether any aspect of the ERP elicited by second words would reflect its semantic association with the first word, and (2) whether, as anticipated on the basis of previous results from experiments using sentences, this ERP effect would be manifested in the N400 component of the ERP independently of the $P 300$. Such a result would extend the usefulness of the $\mathrm{N} 400$ as an index of semantic priming/expectancy from sentence to word pair contexts.

\section{Results}

\section{Subject Ratings of Semantic Relatedness/ Association}

The subjects' semantic relationship ratings for the three different a priori word pair types (highly related, moderately related, and unrelated) are presented in Table 1. While there was a clear difference between subjects' ratings of the related and unrelated pairs, there was no significant difference between their relatedness judgments for the highly and moderately related pairs (chi-square < 1 for first two columns of Table I).

\section{Letter Search Reaction Times}

Subjects generally took over a second to respond to the probe letter, but showed a reduction in reaction time across the experimental halves [first half $1427 \pm 398 \mathrm{msec}$ versus second half $1248 \pm 243 \mathrm{msec}, F(1,10)=7.21, \mathrm{p}<.023$ ]. For both halves of the experiment, subjects responded approximately $300 \mathrm{msec}$ faster on letter present (1182 244 msec) than on letter absent $(1492 \pm 353 \mathrm{msec})$ trials $[F(1,10)=30.14, p<.001]$.

\section{Event-Related Potentials Elicited by Word Pair Stimuli}

The grand average $(n=11)$ ERPs elicited by the word pairs in the delayed letter search task are shown in Figure 1; for each recording site, the ERPs associated with the three a priori relatedness conditions are superimposed. Across all conditions, the initial part of the ERP waveform elicited by first word stimuli was characterized by N100, P138, N190 and P246 components. The N100 component (see midline recordings) was relatively small and inconsistent across subjects; therefore, no further analyses were conducted. The P138 component was largest in amplitude at the parietal midline location and showed a slight tendency to be larger over the right $(3.69 \pm .34 \mathrm{uV})$ than the left $(2.64 \pm$ $.33 \mathrm{uV}$ ) posterior temporal site. This tendency was unaffected by subject's handedness or family history of handedness (also see Goodin, Waltz \& Aminoff 1985; Kutas et al. 1988).

The P138 component was followed by a small N190 component that in part overlapped the following P246 component posteriorly. Following the P246 to the first word was a slow negative shift (at midline frontal site) and a negative-positive-negative sequence (at central and parietal sites). There was no significant main effect of relatedness condition for any ERP component elicited by the first word in each pair.

The ERPs to the second words in a pair also were characterized by P138 and P220 components, albeit both reduced in amplitude relative to those elicited by first words. The amplitude of the second word P220 (mean area 150-250) did not reflect the nature of the semantic association between the words in the pair, although there was a tendency for the most highly related pairings to have a slightly enhanced positivity in the $\mathrm{P} 220$ region, probably reflecting the lack of subsequent negativity.

Following the P220 to the second word, there was a noticeable effect of semantic association/relatedness in the ERP. While all the word types were associated with a

Table 1

\section{A Priori Sentence Category}

\begin{tabular}{|c|c|c|c|c|c|}
\hline & & $\begin{array}{l}\text { Highly } \\
\text { Related }\end{array}$ & $\begin{array}{l}\text { Moderately } \\
\text { Related }\end{array}$ & Unrelated & Sums \\
\hline Subject & 1 & $70.6(.48)$ & $37.3(.46)$ & $2.5(.03)$ & 110.4 \\
\hline Relatedness & 2 & 49.5(.34) & $28.0(.34)$ & $5.4(.06)$ & 82.9 \\
\hline \multirow[t]{3}{*}{ Judgement } & 3 & 15.6(.10) & $8.8(.11)$ & $9.5(.10)$ & 33.9 \\
\hline & 4 & $5.8(.04)$ & $5.4(.06)$ & $13.3(.15)$ & 24.5 \\
\hline & 5 & $5.5(.04)$ & $2.5(.03)$ & $60.3(.66)$ & 68.3 \\
\hline
\end{tabular}

Numbers of sentences that were classified in each a priori and subject-rating category (out of 320 total). Numbers in parentheses show proportion of words receiving each level of subject rating within each of the a priori categories. Mean values over all eleven subjects. 
L. ANT. TEMPORAL

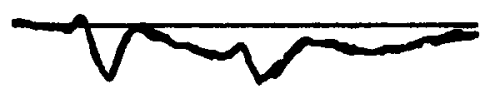

L. POST. TEMPORAL

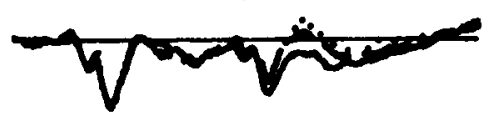

FRONTAL

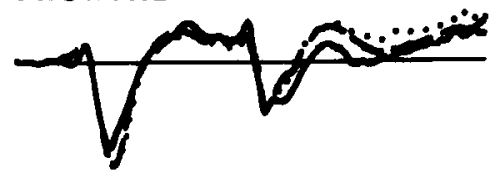

CEnTRAL
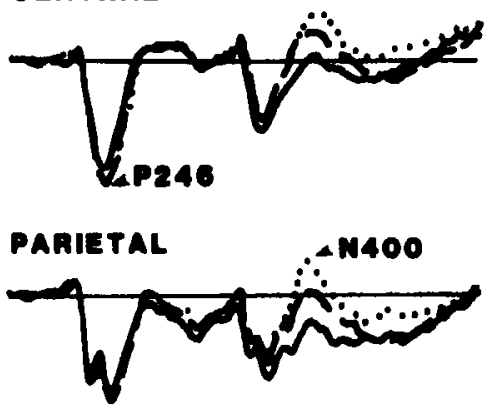

occipital.

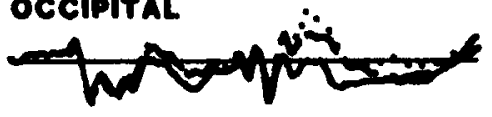

P. ANT. TEMPORAL

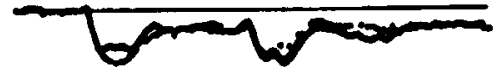

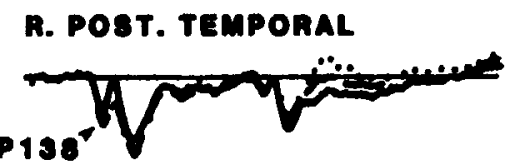

highly related - - - moderately related -........................... unrelated

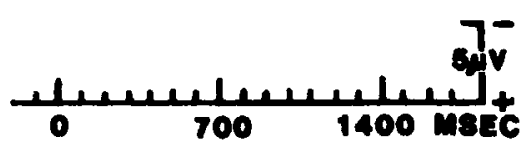

Figure 1: Grand average ERPs ( $n=11)$ elicited by word pairs during the delayed letter search task. The three waveforms superimposed represent ERPs in response to highly related, moderately related, and unrelated word pairs with the degree of relation based on published and experimenter gathered production norms. Negativity is up in this and all subsequent figures.

negative-going potential between 300 and $600 \mathrm{msec}$ poststimulus (the N400 component), its amplitude differed as a function of the word's semantic association with the preceding word. Those second words that were most highly related to the preceding word were associated with a reduced $\mathrm{N} 400$ (or equivalently, with a greater positivity) relative to those that were preceded by less related or wholly unrelated words. Based on previous studies of the N400 scalp distribution, we had decided a priori to measure its amplitude at those sites where the component is typically most evident, namely, midline central to occipital sites, and over the right hemisphere; for these five sites the mean amplitude measure over the interval $350-450$ msec following the second word onset, relative to a 200 msec baseline prior to first word onset, showed a main effect of semantic relation, $F(2,20)=21.5$, epsilon $=0.65$, $\mathrm{p}<.001$ and a semantic relation by electrode interaction, $\mathrm{F}(8,80)=5.45$, epsilon $=.37, \mathrm{p}<.001^{2} \quad$ Pairwise comparisons among the various relatedness conditions showed that the N400 elicited by highly related pairs differed significantly from that elicited by moderately related $(p<.001)$ and unrelated pairs ( $p<.001)$; the N400 to moderately related pairs differed from that to unrelated pairs only marginally $(p<.067)$. Examination of the ERPs in Figure 1 further demonstrates that the $\mathrm{N} 400$ elicited by the second words of unrelated pairs was substantially larger than those elicited by all first word stimuli.

\section{ERPs Averaged According to Subjects' Ratings}

Since all subjects had rated the degree of semantic relatedness for each word pair, ERPs could be averaged according to each individual's ratings. The waveforms in Figure 2 contrast the ERPs associated with word pairs that subjects judged as highly related (rating 1 ) and those that they judged as not very related (ratings 4 and 5). As expected, this subject-based sorting of the ERPs yielded a significant difference between the N400s elicited by highly related and unrelated word pairs [for mean amplitude $350-450$ across the five electrodes $F(1,10)=7.63$, $p<.02$; condition by electrode interaction $F(4,40)=7.95$, $\mathrm{p}<.001$; this average difference of $1.52 \mathrm{uV}$, however, was somewhat smaller than the comparable $\mathrm{N} 400$ difference between highly related and unrelated words as defined a priori $(2.28 \mathrm{uV})$.

Possible evidence for a dissociation between a priori and subject-based ratings of semantic association can be seen by comparing the ERPs elicited by two different a priori classes of word pairs to which subjects gave equivalent ratings. Such a contrast is provided by the waveforms in Figure 3, wherein the ERPs elicited by highly related word pairs are superimposed on those elicited by the average of moderate and unrelated pairings; in each case, only those word pairs that subjects had rated as highly related (ratings of 1 or 2) were included in the averages. Despite the equivalence of subject ratings for these word 
pairs, the second words designated a priori as moderate and unrelated elicited a significantly larger N400 than those that were in the highly related category [for mean amplitude 350-450 main effect of semantic relation $\mathrm{F}(1,10)=22.84, \mathrm{p}<.001$ ] (see Table 2).

\section{Discussion}

The primary aim of this experiment was to determine whether there would be a modulation of the amplitude of the N400 elicited by the second of a pair of words when the semantic relationship or association between them was wholly irrelevant to a subject's assigned task. Since the task-relevant decision was delayed until 1200 msecs after second word presentation and was based on a non-semantic property of the words (letter search), variations in N400 amplitude could be observed as a function of semantic association unconfounded by any overriding, decisionrelated positivity. Under these conditions, all second words elicited a posteriorly-distributed N400 that increased in amplitude as an inverse function of the degree of semantic association with the first word. These results suggest the utility of the present paradigm and variants thereof for inveștigating mechanisms of semantic priming and the organization of semantic memory in situations wherein the experimenter does not want the subject's attention drawn to the semantic processes under study.

The present findings are in line with previous reports that the $\mathrm{N} 400$ response is not limited to words in sentences but can also be elicited by words in pairs or lists (e.g., Bentin et al. 1985; Holcomb 1986). In those studies the N400 was identified as a negative-going wave or inflection superimposed upon a large positive component (P300). It was primarily through its timing and apparent sensitivity to semantic relationships that this negativity was identified as an N400 component. However, it was still not clear whether the N400 wave per se was an index of semantic association that was independent of the overlapping P300 wave. The present results strongly support the view that the ERP priming effects observed with lexical decision and category judgement tasks were due to changes in the $\mathrm{N} 400$ component rather than to variations in the amplitude and latency of a coincident P300 (e.g., Bentin et al. 1985; Boddy 1986). ${ }^{3}$ In addition, these results help explain the reported differences in the scalp distribution of the $\mathrm{N} 400$ in previous sentence versus word pair tasks. In particular, the central-parietal N400 distribution observed here suggests that the apparently more frontal distribution of the
L. ANT. TEMPONAL

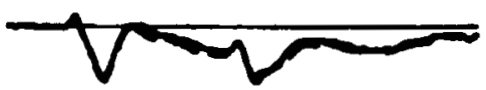

L. POST. TEMPORAL
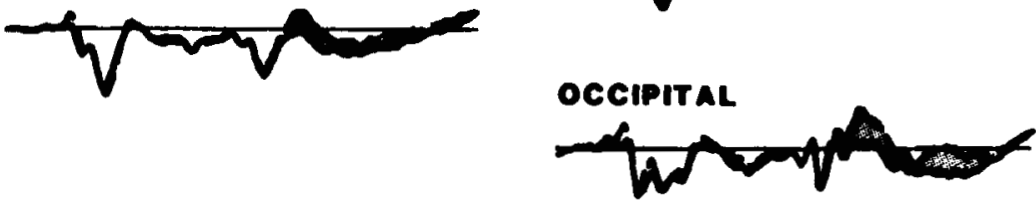

occipital

R. ANT. TEMPORAL

central

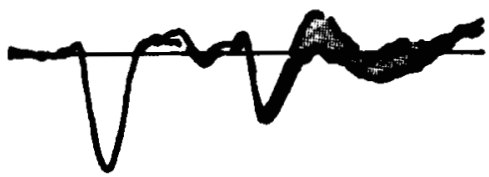

pantetal

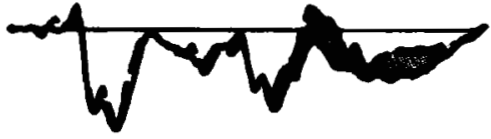

R. POST. TEMPORAL
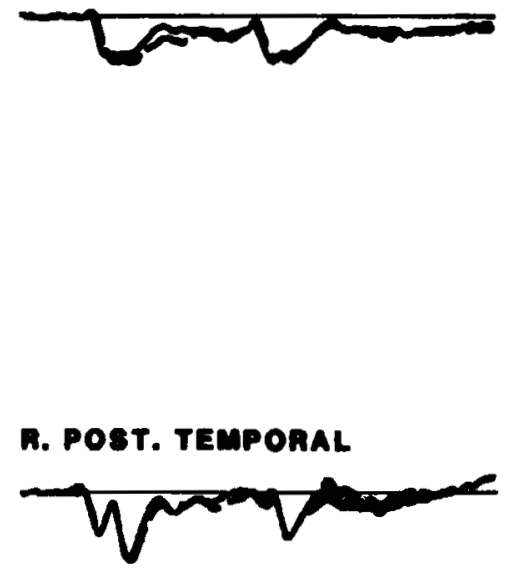

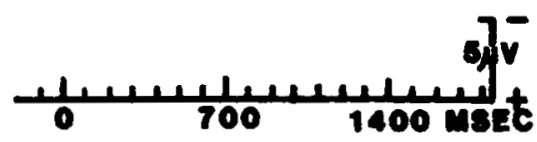




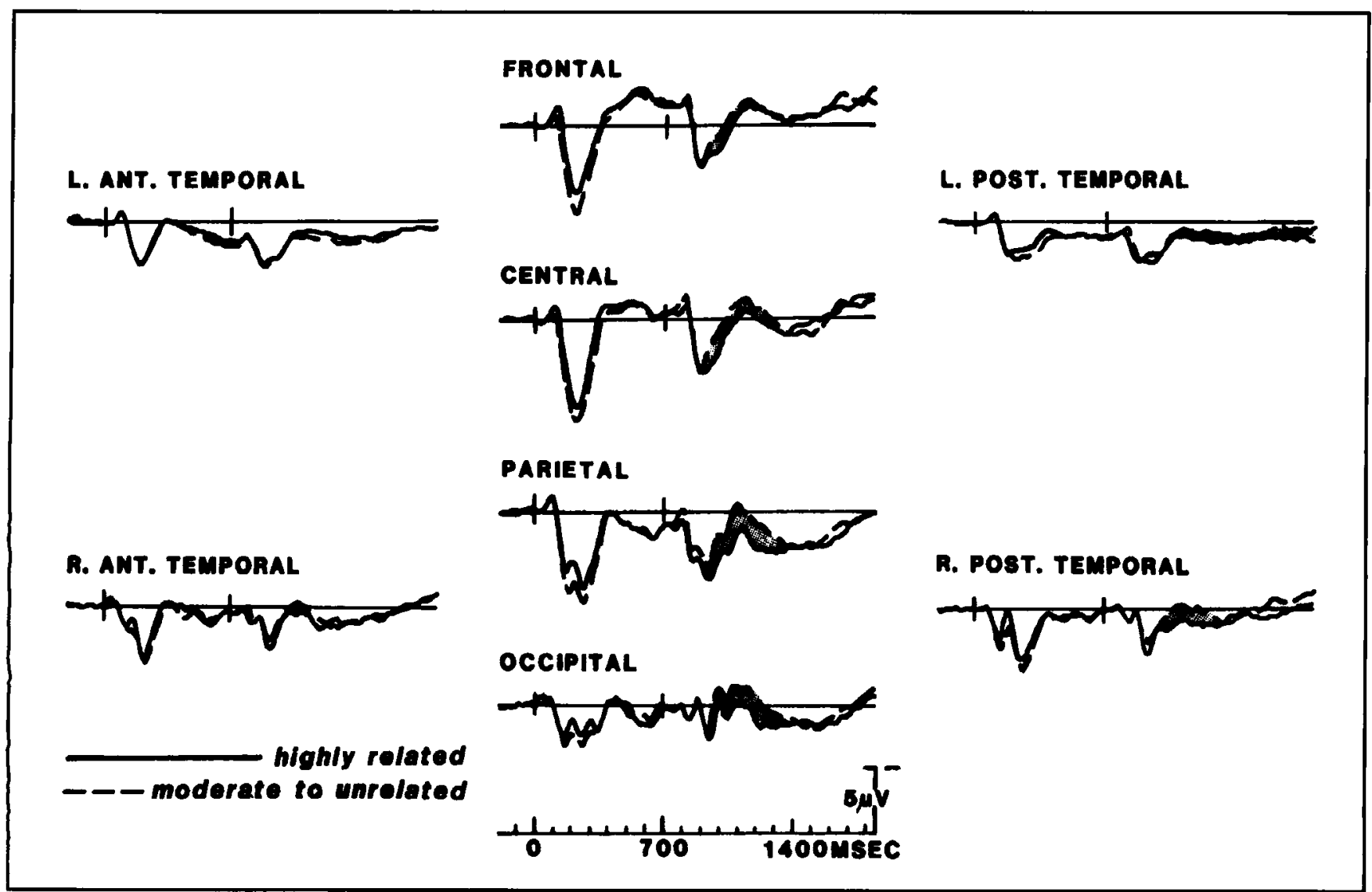

Figure 3: A comparison of the grand average ERPs ( $n=11)$ elicited by highly related word pairs and the average of moderately related and unrelated word pairs during the letter search task, but including only those word pairs that subjects had rated as highly related (ratings of 1 and 2 ) after the recording session.

N400 reported in some of the earlier word pair tasks was probably due to overlap with a P300 component, whose centro-parietal maximum would tend to cancel the N400 at these scalp sites (e.g. Boddy 1986). When no such overlap between the N400 and P300 components is present, as in the current experiment, the N400 elicited by word pairs has the posterior distribution characteristic of those recorded during sentence reading. In fact, both the morphology and anterior-posterior scalp distribution of our word pair N400 were similar to those elicited by content words in sentence contexts in previous studies (e.g. Kutas \& Hillyard 1983; Kutas et al. 1988). ${ }^{4}$

The apparent similarity of the $\mathrm{N} 400$ in the word pair and sentence contexts raises the interesting possibility that semantic priming within sentences is due strictly to the presence of lexical associates rather than to the overall plausibility or predictability of the words. Fischler et al.'s (1983) data showing that the N400 is relatively insensitive to the truth or falsity of a statement but instead reflects the degree of semantic relationship between the subject and the object in a simple proposition are consistent with this view. Similarly, we have observed an effect of semantic association on the $\mathrm{N} 400$ elicited by anomalous words (Kutas et al. 1984). On the other hand, it also seems to be the case that strong contextual constraints in sentences will significantly reduce the $\mathrm{N} 400$ to content words (Kutas et al. 1988; Van Petten \& Kutas, 1987b, submitted). Thus, both contextual constraints and semantic association seem to be reflected in $\mathrm{N} 400$ amplitude measures. Several behavioral researchers are strong advocates of the position that all sentence priming effects can be accounted for in terms of lexical associations between the constituent words (e.g., Bradley \& Forster 1987). The present data point to a similarity between the effects of lexical association and sentence context on N400 amplitude and suggest that further ERP studies can help specify how these factors interact in sentence comprehension.

The present word-pair ERP data indicate that N400 amplitude was a sensitive index of incidental semantic association in a delayed letter search. In this regard, this task is similar to both the lexical decision and naming latency tasks, neither of which logically requires lexical access to word meanings (see Henderson 1982). However, while it is possible to decide that a letter string constitutes a legal word or to pronounce it without contacting its semantic representation, for many years the results obtained with both these tasks were interpreted as reflecting lexical access (see Henderson 1982).

Recently, this view that semantic priming effects are necessarily a consequence of lexical access has been called into question (e.g., Forster 1979; Seidenberg et al. 1984). Some impetus for this interpretative shift has come 
Table 2

\title{
A Priori Categories Subject Ratings
}

$\begin{array}{lllllll} & & \begin{array}{l}\text { Highly } \\ \text { related }\end{array} & \begin{array}{l}\text { Moderately } \\ \text { related }\end{array} & \text { Unrelated } & \begin{array}{l}\text { Highly } \\ \text { related(1) }\end{array} & \begin{array}{l}\text { Unrelated } \\ (4,5)\end{array} \\ \text { Electrode } & \text { Frontal } & -0.50 & -1.72 & -1.88 & -0.90 & -1.97 \\ \text { Site } & \text { Central } & 0.19 & -1.57 & -2.50 & 0.24 & -\mathbf{2 . 1 3} \\ & \text { Parietal } & 2.03 & -0.14 & -1.47 & 1.54 & -0.82 \\ & \text { Occipital } & 0.29 & -1.49 & -2.55 & -0.32 & -1.97 \\ & \text { L.ant.temp } & 0.87 & 1.12 & 1.24 & 0.79 & 1.23 \\ & \text { R.ant.temp } & 1.23 & 0.89 & 0.77 & 0.88 & 0.74 \\ & \text { L.post.temp } & 0.95 & -0.31 & -0.68 & 0.70 & -0.52 \\ & \text { R.post.temp } & 1.16 & 0.07 & -0.75 & 0.72 & -0.36\end{array}$

\begin{abstract}
Mean amplitude of $\mathrm{N} 400$ to second words (over interval $350-450 \mathrm{msec}$ post stimulus onset) averaged according to a priori and subject ratings of semantic association with first words.
\end{abstract}

from the finding that the relationship between several lexical variables and reaction time varies significantly as a function of task (Balota \& Lorch 1986; Lupker 1984; Seidenberg et al. 1984; West \& Stanovich 1982). This has been problematic because major goals for this field of study have been to discover the underlying organizational principles of lexical access and semantic memory independent of assigned task. On the whole, priming effects obtained with the lexical decision task have been sensitive to a wider range of variables than have those resulting from pronunciation tasks. Moreover, even when a variable has been shown to influence latencies in both tasks, its effect is typically greater in the lexical decision task. Such results have been used to argue that decision processes having little to do with lexical access accentuate the semantic priming effect on RT in the lexical decision task, and that results from this task have questionable value in testing hypotheses about ease of lexical access. Proponents of this latter view contend that the semantic priming effect can only be attributed to the lexicon if a pronunciation task is used (e.g., Seidenberg et al. 1984). Their assumption is that postlexical processing is unlikely to facilitate the naming response because the subject does not have to make a word/nonword decision. However, it has been shown that even naming latency measures are influenced by task-specific factors unrelated to lexical access Balota \& Chumbley 1985). Finally, Norris (1986) has proposed that context effects can be explained without resort to lexical priming. While it would be premature to propose that the N400 is a more direct measure of lexical access or word recognition, the present ERP paradigm provides an electrophysiological probe of semantic association that is not subject to the decision-related variables influencing lexical decision or naming latency tasks.

Although there has been considerable overlap in the variables that influence behavioral measures of semantic priming and those that influence $\mathrm{N} 400$ amplitude, the present results suggest at least a partial dissociation between the mechanisms underlying $\mathrm{N} 400$ amplitude variation and lexical decision latencies. Both lexical decision latencies and $\mathrm{N} 400$ amplitudes following target words are altered by the presence of related primes. However, unlike the $\mathrm{N} 400$, the reduction in lexical decision latencies does not appear to reflect systematically the degree of the prime-target relationship as measured by word association norms (e.g., Koriat 1981). Since our naming latency measure yielded a similar graded priming effect with the same stimuli, it may be that the N400 measure is more closely related to those aspects of lexical processing that affect pronunciation latencies as opposed to lexical decision times.

It is noteworthy that the $\mathrm{N} 400$ was highly sensitive to semantic association even though the subjects were not informed of such relationships nor required to analyze them. Thus, it appears that reading and "remembering" the prime and target for a subsequent letter search are sufficient to yield ERP manifestations of semantic priming. Given the relatively long SOA between prime and target words in the present experiment, we cannot be certain that at least some of the N400 effect was not due to subjects' use of a predictive strategy (e.g. Neely 1977; de Groot 1984). While the most direct test of this hypothesis would be to conduct the present experiment with very short SOAs, the ERP results of a lexical decision paradigm with prime-target pairs indicate that N400-like effects occur with SOAs as short as $200 \mathrm{msec}$ (Boddy 1986). However, it is also important to note that the ERP effect in the present experiment did not appear to be as large as that generally obtained for final words in sentence contexts or for isolated word pairs when the task required a relatedness 
judgement (Kutas 1984; Kutas 1985; Kutas \& Van Petten, in press). On present evidence we can tentatively hypothesize that there is an automatic component to semantic priming that is reflected in the $\mathrm{N} 400$ elicited in this word pair task, but that like behavioral priming effects, N400 amplitude can be modulated by attentional manipulations as well (e.g., de Groot 1984; Henik, Friederich \& Kellog 1983; Kaye \& Brown 1985; Neely 1977; Parkin 1979; Smith 1979; Smith, Theodor \& Franklin 1983; Tweedy \& Lapinski 1977). This ERP measure may be used to probe the automaticity of contextual influences, a problem that has been relatively impervious to investigation.

The present results do not establish unequivocally whether or not subjects were consciously aware of the semantic relations between the words while performing the delayed letter search task. One aspect of our data, however, suggests that even if they were, it was probably not a conscious strategy that was reflected in the ERP priming effects. If the ERP effects were a consequence of subjects' realizations of the semantic/associative relation between words, we would have expected larger ERP effects when the data were sorted according to each individual's relatedness ratings. The fact that this was not the case is consistent with the view that the mechanisms leading to facilitated recognition in a typical priming task are not necessarily the same as those engaged during a semantic rating or categorization task (see Koriat 1981). In this regard it is noteworthy that the stimuli in the present experiment had been initially classified as related or unrelated on the basis of production associations, namely, the first word that came to mind after hearing or seeing a word. This procedure is different in several respects from asking subjects to rate the relation between two words. Data for production norms are gathered with an emphasis on speed whereas relatedness judgements are done with more contemplation. This difference in the speed of processing in the two tasks may account for the observed differences in the a priori and subjects' ratings of semantic relatedness.

Another intriguing possibility is that the differential results obtained with the association production and rating procedures is attributable to the need for speech production. By this line of reasoning, the N400 seems to be a better index of the use of the semantic lexicon for production than it is for comprehension. A similar dissociation has been observed by Milberg and Blumstein in investigations of semantic priming in aphasics. Of relevance here is their finding that Wernicke's aphasics exhibited large semantic priming effects in both auditory and visual lexical decison tasks although they were incapable of performing a semantic judgment task with the same stimuli reliably (Milberg \& Blumstein 1981; Blumstein, Milberg \& Shrier 1982).

We have observed a similar dissociation between comprehension and priming (in this case indexed by the N400 measure) in a subgroup of commissurotomized patients (Kutas, Hillyard \& Gazzaniga, 1988). In that experiment, five commissurotomized individuals were presented tasks with sentence fragments that were completed by a word flashed to either the left or right visual field. After each sentence, the patients were required to point manually at a card containing the words "sense" and "nonsense", to reflect their judgment about the congruity of the terminal word. All five of the patients were capable of performing this sense/nonsense judgment task with greater than chance accuracy following words flashed to either the right or left hemisphere. In a second task, the patients again listened to sentence fragments, this time completed by two words flashed simultaneously to the right and left visual fields while ERPs were recorded. The measure of priming in this task was the comparison of ERPs elicited by semantic anomalies versus congruous endings. In sharp contrast to the behavioral results, all five patients elicited an $\mathrm{N} 400$ following semantic anomalies flashed to the left hemisphere, but only two showed N400s when the anomaly was flashed to the right hemisphere. The two patients who produced N400s in response to right hemisphere anomalies differed from the others in being able to control speech via the right hemisphere. Therefore, we hypothesized that there might be different brain organizations subserving semantic processing, one that leads to semantic priming effects and is necessary for speech control, and another that does not underlie priming but can be used to comprehend. While this interpretation awaits further testing, the data do suggest a dissociation between the semantic processes that lead to $\mathrm{N} 400$ generation (and RT facilitation) and those that are used to make semantically based (e.g., sense/nonsense) judgments.

\section{Methods}

\section{Subjects}

Eleven young adults (seven male, age range 18-24 years old) were paid for participating in the experiment. Six of the subjects were right-handed and five left-handed according to self-report and the Edinburgh Inventory (Oldfield 1971). One of the right-handers and four of the lefthanders had left-handed relatives in their immediate family.

\section{Stimuli}

There were a total of 320 word pairs; of these, $46 \%$ were classified as highly related semantically, $25 \%$ were moderately related and the remaining $29 \%$ were semantically unrelated. In most cases, the degree of relation between the words was determined from association and category norms of word production (Battig \& Montague 1969; Postman \& Keppel 1970). Additional word pairs were generated and classified as to semantic association on the basis of experimenter judgments and usage by previous investigators (e.g., Meyer \& Schvaneveldt 1971). These a priori semantic classifications were validated in behavioral studies with two independent groups of subjects. In 
the first, eleven subjects (different from those in the present experiment) were asked to produce an associate to each of the 320 words as quickly as possible. For this group of subjects, the probability that the second word chosen by the experimenter was given as a response to the first word was 0.47 for the highly related condition, 0.08 for the moderately related condition, and 0.00 for the unrelated condition.

The presence of semantic priming effects with these stimuli was also verified by a second group of subjects in a naming task. Sixteen subjects were presented with the same 320 word pairs used in the present experiment. All aspects of stimulus presentation (e.g., duration and stimulus onset asychrony) were identical to those in the present experiment. However, the subject's task was to say aloud the second word of each pair as quickly as possible. The results of this naming latency task showed that the second words of highly related word pairs were pronounced significantly faster than words that were only moderately related $(p<.001)$ and these in turn were named significantly faster $(p<.008)$ than words that were semantically unrelated (verbal RTs were 555, 575 and $587 \mathrm{msec}$, respectively).

The second word of each highly related pair averaged 4.99 letters in length (range 2-11) and had a median frequency in the English language of 93 . The second word of each moderately related pair averaged 5.43 letters in length (range 3-12) and had a median frequency in the English language of 60 . The second word of each unrelated pair averaged 5.64 letters in length and had a median frequency of 60 .

\section{Recording system}

EEG activity was recorded from eight scalp electrodes, each referred to linked mastoids. Four were placed according to the International 10-20 system at frontal $(\mathrm{Fz})$, central $(\mathrm{Cz})$, parietal $(\mathrm{Pz})$ and occipital $(\mathrm{Oz})$ midline locations. Symmetrical anterior temporal electrodes were placed halfway between $\mathrm{F} 7$ and $\mathrm{T} 3$ and $\mathrm{F} 8$ and T4 sites, respectively. Symmetrical posterior temporal electrodes were placed lateral (by $30 \%$ of the interaural distance) and $12.5 \%$ posterior to the vertex. In addition, eye movements were monitored via an electrode placed below the right eye and referred to the mastoids for vertical movements and blinks, and via a right to left canthal bipolar montage for horizontal movements.

The midline and EOG recordings were amplified with Grass 7P122 preamplifiers (system bandpass DC to $35 \mathrm{~Hz}$, half-amplitude cutoff). The EEG from the lateral scalp leads were amplified with Grass 7P511 preamplifiers modified to have an 8 second time constant (high frequency half amplitude cutoff $=60 \mathrm{~Hz}$ ).

Analog-to-digital conversion of the EEG, EOG and stimulus trigger codes was performed on-line by computer. A 1024 msec epoch of EEG beginning $100 \mathrm{msec}$ before the onset of each stimulus was analyzed at a sampling rate of $250 \mathrm{~Hz}$. In addition, these data were used to generate averages of $2048 \mathrm{msec}$ epochs beginning 200 msec prior to the presentation of the first word in each word pair.

All data were initially analyzed by repeated measures ANOVA. The degrees of freedom of each $F$ ratio were computed using the Greenhouse-Geisser procedure for controlling Type I error in repeated measures designs; the correction factor (i.e., epsilon) is reported along with the original degrees of freedom.

\section{Procedure}

Words were displayed in the form of brightened dot matrices on a CRT controlled by an Apple II microcomputer. All words were exposed for $132 \mathrm{msec}$ and ranged in length from one to thirteen letters. Subjects sat approximately 33" from the screen.

Subjects were tested in one session that lasted between two and two and a half hours, while reclining in a comfortable chair. Prior to the ERP recordings each subject was given a reading test of speed and comprehension, and the level II pronunciation and spelling subtests of the Wide Range Achievement Test as well as a handedness questionnaire. These were used to ensure that our subjects were not dyslexic. Neither the reading, pronunciation or spelling scores correlated with any of our ERP measures and will not be discussed further.

Subjects were presented with a total of 320 word pairs each followed by a letter, in four blocks of 80 pairs each. The specific order of the four quarters of 80 trials was counterbalanced across subjects. For each word pair, subjects saw the first word followed $700 \mathrm{msec}$ (onset to onset) by the second word. Following the second word onset with a delay of $1200 \mathrm{msec}$, a letter punctuated by a question mark was flashed for $250 \mathrm{msec}$. The subject's task was to depress one key on a keypad if the letter had been present in either or both of the words and to depress a different key if the letter had not been present in either word of the pair. Responses were performed by the first and third fingers of the dominant hand. The presentation of the next trial was contingent upon a response to the previous trial and followed the key depression by 1800 msec.

Following the ERP recording session each subject was shown all 320 pairs again and asked to rate the degree of semantic relatedness or associaton between the pairings on a 5-point scale with " 1 " meaning very highly related and " 5 " indicating not at all related.

\section{Notes}

1. For example, "lion" primes "stripes" through the mediating word "tiger" which is not actually presented.

2. These results were unaffected by our restricting the N400 measure to these five electrodes (across all eight electrode sites, main effect of semantic relation, $F(2,20)=18.69$, epsilon $=0.67$, $\mathrm{p}<.001$; semantic relation by electrode interaction, $\mathrm{F}(14,140)=6.38$, epsilon $=.28, \mathrm{p}<.0011$.

3. The present data are consistent with previous studies of the ERP effects of semantic association within the 250 to $500 \mathrm{msec}$ 
range except for the report of Polich (1985).Polich compared ERPs elicited by the last words in seven-word lists wherein all seven words were members of the same semantic category for $50 \%$ of the trials and the last word deviated from the category of the first six words for the remaining $50 \%$ of the trials. The detailed characteristics of the stimuli (e.g., frequency of occurrence in English, prototypicality, instance dominance, etc.) were not provided. These may be important because, in concept, Polich's experiment is not significantly different from that reported by Harbin et al. (1984), who also compared ERP effects of category match and mismatch. Presumably there was substantial overlap between the stimuli used by Polich and Marsh et al., since both studies employed category members from the Battig and Montague norms (1969). The Polich and Harbin et al. studies differed in 1. list length (seven versus five); 2 . stimulus onset asynchrony (533 versus $1000 \mathrm{msec}$ ); 3 . how subject was informed of the final word occurrence; 4 . probability of semantic association $(50 \%$ versus 15\%); 5 . task (reading versus button press for match). Based on the results of other ERP priming studies that examined some of these variables, it is unlikely that either SOA (Boddy 1986; Kutas 1987), probability of semantic association (Holcomb, in press), or task can account for the total lack of an N400 mismatch effect in the Polich study. One likely explanation is based on two findings concerning the N400: (1) in sentences, congruent but relatively unpredictable words are capable of eliciting an N400 (Kutas \& Hillyard 1984), and (2) repeated words yield smaller negativities on second presentation (e.g., Halgren \&Smith 1987). With regard to the first finding, it would be important to know the strength of association between the category name and the seventh member of the category (i.e., instance dominance). The congruent lists were the Battig and Montague norms. That is, the first word in a seven word list was the most frequent instance of a category and each word thereafter was a less frequent instance. Thus, the seventh word in each list was a less typical exemplar than the preceding six items and since instance dominance and word frequency are correlated (Chumbley 1986; Mervis, Catlin \& Rosch 1976), it probably was also a less frequent word. Hence these seventh words were relatively more unexpected and unprimed and would thereby be associated with less positivity (i.e., more of an N400) than if the seventh word had been a more typical category member or frequent word. With regard to the repetition results cited above, it would be important to know whether or not the seventh word of the incongruent lists had been presented as a member of a previous category or had been a member of a previously presented category even if the word itself had not been shown. Repetition of the incongruent seventh word, either in concept or actuality, would tend to reduce the amplitude of the N400 it elicited. By this line of reasoning, the larger-than- predicted N400 to the less typical members of the congruent lists and the smallerthan-predicted $\mathrm{N} 400$ to the incongruent seventh words may account for the equivalent $N 400$ s to category matches and mismatches in the Polich study.

4. It is important to note that we are not necessarily arguing that all N400s must have a posterior distribution. In fact, we have previously reported that the distribution of the N400 appears more frontal when words are presented at fast rates (e.g., from simultaneous to ten per second) (Van Petten \& Kutas 1987a; Kutas 1987).

\section{Acknowledgments}

Sincere thanks to $C$. Van Petten for her helpful comments on several versions of this manuscript and J.C. Hansen for providing extremely user-friendly software for data reduction and analyses. This work was supported by grants from NINCDS (NS-17778), NSF (BNS83-09243) and NICHD (HD22614). M.K. is supported by an RSDA from NIMH (MH00322).

\section{References}

Antos, S.F. Processing facilitation in a lexical decision task. Joumal of Experimental Psychology: Human Perception and Performance,1979, 5, 527-545.

Balota, D.A. and Chumbley, J.I. Are lexical decisions a good measure of lexical access? The role of word frequency in the neglected decision stage. Journal of Experimental Psychology: Human Perception and Performance, 1984, 10, 340-357.

Balota, D.A. and Chumbley, J.I. The locus of word-frequency effects in the pronunciation task: Lexical accesss and/or production? Journal of Memory and Language, 1985, 24, 89-106.

Balota, D.A. and Lorch, R.F., Jr. Depth of automatic spreading activation: Mediated Priming effects in pronunciation but not in lexical decision. Journal of Experimental Psychology: Learning, Memory, and Cognition, 1986, 12, 3, 336-345.

Battig, W.F. and Montague, W.E. Category norms for verbal items in 56 categories: A replication and extension of the Connecticut category norms. Joumal of Experimental Psychology Monographs, 1969, 80, (3, Pt.2).

Bentin, S., McCarthy,G. and Wood,C.C. Event-related potentials associated with semantic priming. Electroencephalography and Clinical Neurophysiology, 1985, 60, 343-355.

Blaxton, T.A. and Neely, J.H. Inhibition from semantically related primes: Evidence of a category-specific inhibition. Memory and Cognition, 1983, 11, 500-510.

Blumstein S.E., Milberg, $W_{\text {, }}$ and Shrier, R. Semantic processing in aphasia: evidence from an auditory lexical decision task. Brain and Language, 1982, 17, 2, 301-315.

Boddy, J. Evoked potentials and the dynamics of language processing. Biological Psychology, 1981, 13, 125-140.

Boddy, J. Event-related potentials in chronometric analysis of primed word recognition with different stimulus onset asynchronies. Psychophysiology, 1986, 23, 2, 232-245.

Boddy, J. and Weinberg,H. Brain potentials, perceptual mechanism and semantic categorization. Biological Psychology, 1981, $12,43-61$.

Bradley, D.C. and Forster, K.I. A reader's view of listening. Cognition, 1987, 25.

Brown, A.S. Inhibition in cued retrieval. Joumal of Experimental Psychology: Human Learning and Memory, 1981, 7, 204-215.

Chumbley, J.I. The roles of typicality, instance dominance, and category dominance in verifying category membership. Journal of Experimental Psychology: Learning, Memory and Cognition, $1986,12,2,257-267$.

Coles, M.G.H., Gratton, G., Bashore, T.R., Eriksen, C.W. and Donchin, E. A psychophysiological investigation of the continuous flow model of human information processing. Journal of Experimental Psychology: Human Perception and Performance, $1985,11,529-553$.

De Groot, A.M.B. Primed lexical decision: Combined effects of the proportion of related prime-target pairs and the stimulus 
onset asynchrony. Quarterly Journal of Experimental Psychology, 1984, 36A, 253-280.

Donchin, E., Karis, D., Bashore, T.R., Coles, M.G.H. Coles, and Gratton, G. Cognitive psychophysiology and human information processing. In $\mathbf{M}$. Coles, E. Donchin and S. Porges (Eds.), Psychophysiology: Systems, Processes and Applications, 1986, New York: Guilford Press, 244-267.

Duncan, C.P. and Wood, G. Norms for successive word associations, Psychonomic Monograph Supplements, 1966, 1, 7, 203-206.

Fischler, I., Bloom, P.A., Childers, D.G., Roucos, S.E. and Perry, N.W., Jr. Brain potentials related to stages of sentence verification. Psychophysiology, 1983, 20, 400-409.

Fischler,I., Childers,D.G., Achariyapaopan,T. and Perry, N.W.Jr. Brain potentials during sentence verification: Automatic aspects of comprehension. Biological Psychology, 1985, 21, 83-106.

Forster, K. Levels of processing and the structure of the language processor. In W.E. Cooper and E.C.T. Walker (Eds.), Sentence Processing: Psycholinguisitc studies presented to Merrill Garrett, 1979, Cambridge, MA: MIT Press.

Forster, K. Priming and the effects of sentence and lexical contexts on naming time: Evidence for autonomous lexical processing. Quarterly Journal of Experimental Psychology, 1981, $33 A, 465-495$.

Goodin, D.S., Waltz, D.A. and Aminoff, M.J. Task-dependent hemisphere asymmetries of the visual evoked potential. Neurology, 1985, 35, 378-384.

Grosjean, F. Spoken word recognition and the gating paradigm. Perception and Psychophysics, 1980, 28, 267-283.

Halgren, E., and Smith, M.E. Cognitive evoked potentials as modulatory processes in human memory formation and retrieval. Human Neurobiology, 1987, 6, 129-140.

Harbin, T.J., Marsh G.R. and Harvey M.T. Differences in the late components of the event-related potential due to age and to semantic and non-semantic tasks. Electroencephalography and Clinical Neurophysiology, 1984, 59, 489-496.

Henderson,L. Orthography and Word Recognition in Reading, 1982, London: Academic Press.

Henik, A., Friedrich, F.J. and Kellogg, W.A. The dependence of semantic relatedness effects upon prime processing. Memory and Cognition, 1983, 11, 366-373.

Hillyard, S.A. and Hansen, J.C. Attention: electrophysiological approaches: In M. Coles, E. Donchin and S. Porges (Eds.), Psychophysiology: Systems, Processes and Applications, 1986, New York: Guilford Press, 227-243.

Hillyard, S.A. and Picton, T.W. Electrophysiology of cognition. In F. Plum( Ed.), Handbook of Physiology, Section 1: The Nervous System Volume 5, Higher Functions of the Nervous System, Part 2, American Physiological Society, 1987, 519-584.

Holcomb, P.J. ERP correlates of semantic facilitation. In W.C. McCallum, R. Zappoli and F. Denoth (Eds.). Electroencephalography and Clinical Neurophysiology Supplement 38, Cerebral
Psychophysiology: Studies in Event-Related Potentials, 1986, Amsterdam: Elsevier, 320-322.

Holcomb, P.J. Automatic and attentional processes: An eventrelated potential analysis of semantic priming, Brain and Language, (in press).

Kaye, D.B. and Brown, S.W. Levels and speed of processing effects on word analysis. Memory and Cognition, 1985, 13,5, 425-434.

Koriat, A. Semantic facilitation in lexical decisions as a function of prime-target association. Memory and Cognition, 1981, 9, 587-598.

Kutas, M. Language processing and the N400 wave. Paper presented at the Third International Conference on Cognitive Neuroscience, Bristol, England., 1984.

Kutas, M. ERP comparisons of the effects of single word and sentence contexts on word processing. Psychophysiology, 1985, $22,5,575-576$.

Kutas, M. Event-related brain potentials (ERPs) elicited during rapid serial visual presentation of congruous and incongruous sentences. In: R. Johnson, Jr., R. Parasuraman and J.W. Rohrbaugh (Eds.), Current Trends in Event-Related Brain Potential Research (Electroencephalography and Clinical Neurophysiology, Supplement 40), 1987, 406-411.

Kutas, M. and Hillyard,S.A. Brain potentials during reading reflect word expectancy and semantic association. Nature, 1984, 307, 161-163.

Kutas, M., Hillyard, S.A. and Gazzaniga, M.S. Processing of semantic anomaly by right and left hemispheres of commissurotomy patients: Evidence from event-related brain potentials. Brain, 1988, 111, 553-576.

Kutas, M., Lindamood, T. and Hillyard, S.A. Word expectancy and event-related potentials during sentence processing. In S. Kornblum and J.Requin (Eds.), Preparatory States and Processes, 1984, New Jersey: Erlbaum Press, 217-238.

Kutas, M. and Van Petten, C. Event-related brain potential studies of language. In P.K. Ackles, J.R. Jennings, and M.G.H. Coles (Eds.), Advances in Psychophysiology,(in press), Volume 3. Greenwich, Connecticut: JAI Press, Inc.

Kutas, M., Van Petten, C. and Besson, M. Event-related potential asymmetries during the reading of sentences. Electroencephalography and Clinical Neurophsyiology. 1988, 69, 218-233.

Lorch, R.F., Jr., Balota, D.A. and Stamm, E.G. Locus of inhibition effects in the priming of lexical decisions: Pre- or Postlexical access? Memory and Cognition, 1986, 14,2, 95-103.

Mervis, C.B., Catlin, J. and Rosch, E. Relationships among goodness-of-example, category norms, and word frequency. Bulletin of the Psychonomic Society, 1976, 7, 283-284.

Meyer, D.E. and Schvaneveldt, R.W. Facilitation in recognizing pairs of words: Evidence of a dependence between retrieval operations. Journal of Experimental Psychology, 1971, 90. 227234.

Meyer,D.E.,Schvaneveldt,R.W. and Ruddy,M.G. Functions of 
graphemic and phonemic codes in visual word recognition. Memory and Cognition, 1974, 2, 309-321.

Meyer, D. E., Schvaneveldt, R.W. and Ruddy, M.G. Loci of contextual effects on visual word recognition. In P.M.A. Rabbitt and S. Dornic (Eds.), Attention and Performance, 1975, V, New York: Academic Press.

Milberg, W. and Blumstein, S.E. Lexical decision and aphasia: evidence for semantic priming. Brain and Language, 1981, 14, $2,371-385$.

Neely, J.H. Semantic priming and retrieval from lexical memory: Roles of inhibitionless spreading activation and limited-capacity attention. Journal of Experimental Psychologv:General, 1977, 106, 226-254

Norris, D. Word recognition: Context effects without priming. Cognition, 1986, 22, 93-136.

Oldfield, R. The assessment and analysis of handedness: The Edinburgh Inventory. Neuropsychologia, 1971, 9. 97-113.

Parkin, A.J. Specifying levels of processing. Quarterly Journal of Experimental Psychologu. 1979, 31, 179-195.

Picton, T.W. and Stuss, D.T. Event-related potentials in the study of speech and language: a critical review. In D.N. Caplan, A.R. Lecours \& A.M. Smith (Eds.), Biological Perspectives on Language, 1984, Cambridge: MIT Press, 303-360.

Polich, J.M. Semantic categorization and event-related potentials. Brain and Language, 1985, 26. 304-321.

Posner, M.I. and Snyder, C.R.R. Attention and cognitive control. In R.L. Solso (Ed.), Information Processing and Cognition: the Loyola Symposium, 1975a, Hillsdale,N.J.: Erlbaum.

Posner, M.I. and Snyder, C.R.R. Facilitation and inhibition in the processing of signals. In P.M.A. Rabbitt and S.Dornic (Eds.), Attention and Performance $V, 1975 \mathrm{~b}$, New York: Academic Press, 669-681.

Postman, L. and Keppel, G. Eds., Norms of Word Association. 1970. New York: Academic Press.

Rugg, M.D., Kok, A., Barrett, G., and Fischler, I. ERPs associated with language and hemispheric specialization. In W.C. McCallum, R. Zappoli and S. Doneth (Eds.), Cerebral Psychophysiology: Studies in Event-Related Potentials, Electroencephalography' and Clinical Neturophysiology. Supplement 38,1986, Amsterdam, North-Holland: Elsevier.

Schustack, M.W., Ehrlich, S.F. and Rayner, K. Local and global sources of contextual facilitation in reading. Journal of Memory and Language. 1987, 26.3, 322-340.

Seidenberg, M.S., Waters, G.S., Sanders, M. and Langer P.L. Preand postlexical loci of contextual effects on word recognition Memory and Cognition, 1984, 12, 315-328.

Smith, M.C. Contextual facilitation in a letter search task depends on how the prime is processed. Joumal of Experimental Psychology: Human Perception and Psychophysics, 1979, 5, 239251.

Smith,M.C., Theodor,L. and Franklin,P.E. The relationship be- tween contextual facilitation and depth of processing. Journal of Experimental Psychology: Learning,Memory and Cognition, $1983,9,697-712$.

Swinney, D. The process of language comprehension: an approach to examining issues in cognition and language. Cognition, 1981, 10, 307-312.

Tweedy, J.R. and Lapinski, R.H. Facilitating word recognition: Evidence for strategic and automatic factors. Quarterly Journal of Experimental Psychology, 1981, 33A, 51-59.

Van Petten, C. and Kutas, M. Ambiguous words in context: An event-related potential analysis of the time course of meaning activation, Journal of Memory and Language, 1987a, 26, 188208.

Van Petten, $C$. and Kutas, $M$. Interactions between word frequency and sentence context determine $\mathrm{N} 400$ amplitude. Paper presented at the Fourth International Conference on Cognitive Neuroscience, 1987b, Dourdan, France.

Van Petten, C. and Kutas, M. Interactions between sentence context and word frequency, (submitted).

West, R.F, and Stanovich, K.E. Source of inhibition in experiments on the effect of sentence context on word recognition. Journal of Experimental Psychology: Learning, Memory, and Cognition, 1982, 8, 385-399. 